\title{
Improving the effectiveness of anchoring underground structures in permafrost areas
}

\author{
Aleksandr Galkin ${ }^{1, *}$ and Vladimir Pankov ${ }^{2}$ \\ ${ }^{1}$ Melnikov Permafrost Institute SB RAS, 36, Merzlotnaya street., Yakutsk, 677010, Russia \\ ${ }^{2}$ North-Eastern Federal university, 58, Belinsky street, Yakutsk, 677000, Russia
}

\begin{abstract}
A new method of anchoring underground structures in permafrost areas, utilizing full anchors whose locks are based on the property that dispersed frozen rocks can significantly change their firmness depending on temperature, is considered. A new condition of energy efficiency of the use of this method is formulated. Simple engineering formulas, on whose basis the assessment of the non-productive and productive energy expenses during the formation of the anchor lock, were devised. It was determined that in many cases relevant for practice, the non-productive energy expenses can constitute up to $30 \%$ of the productive energy expenses. A conclusion was made that in order to increase the efficiency and to expand the area of application of the new anchoring method in the mine workings of the permafrost areas built in the dispersed frozen rocks, it is necessary to search for technical and technological solutions to decrease the non-productive energy expenses in the front part of the anchor lock.
\end{abstract}

\section{Introduction}

Anchorage of mine workings of underground structures in the permafrost areas bored through the dispersed frozen rocks has an array of peculiarities which need to be considered when determining the expected loads on the anchorage and choosing the type and parameters of the anchorage [1, 2, 3, 4, 5]. A typical kind of dispersed frozen rocks is, for example, icy sandstone which includes quartz sand, cementing ice, non-frozen water, and air. That is, dispersed frozen rocks are a multi-phase material whose matrix, composed primarily of ice and water, constantly changes with the change of temperature and applied load $[6,7,8,9,10,11]$. At that, only one type of ice is usually present in the pores - in its most common hexagonal form - while non-frozen water is encountered in two states: strongly bound and loosely bound water [11]. Strongly bound water appears as a water film surrounding mineral particles, held together through intermolecular forces, which prevent it from freezing even in very low temperatures [12]. Loosely bound water can freely move in the pores and freezes easily. Due to the presence of ice and non-frozen water the strength of frozen dispersed rocks significantly depends on the temperature. When the temperature decreases, a part of weakly bound water will be freezing, thus increasing the cementing role of the ice and increasing the strength of the rock. In the literature review [13] all

\footnotetext{
* Corresponding author: afgalkin@yandex.ru
} 
experimental research conducted in the last fifty years was analyzed in detail and it was demonstrated that functionally, this relationship can be described using two types of simple functions for most types of rocks: power function and linear function.

It is worth noting that individual types of dispersed rocks have a "zero" strenght at positive temperatures. During exploitation of underground structures this leads to collapses and cavern formation. For this reason, underground structures bored in such rocks are used only in negative temperatures. But even in this case, because the temperature in the mine workings varies across a wide range during the cold part of the year (from $-30^{\circ} \mathrm{C}$ to $0^{\circ} \mathrm{C}$ ) the mine workings, especially those used for supplying air, need to be anchored and thermally protected. Among effective ways of anchoring underground structures in permafrost areas is anchor fix combined with thermal insulation $[4,14,15,16,17]$. In the work [18] an original and promising method of anchor fixing of mine working bored in dispersed rocks is proposed. The authors of the patent propose using a specific characteristic of this type of rocks that they can significantly change their properties with temperature to form a reliable anchor lock. It is advised to thaw rocks around the lock of a tube-shaped anchor, lowering their strength to "zero", and to push the anchor lock into the rocks using a non-explosive material based on calcium oxide which emits a large amount of heat when solidifying (for example, HPC-2). The material would be placed in a destroyable ampule in the lock part with cuts to the tube created beforehand which would be forming the teeth of the anchor lock, of which there would be no fewer than two. After the end of the chemical reaction, freezing of the thawed rocks takes place around the anchor lock and because the diameter of the opening of the teeth of the anchor lock is greater than the diameter of the tube, the anchor will be safely locked into the frozen rocks. At that, all of the energy expended during the solidification of HPC-2 is used to heat the rocks and push in the anchor lock teeth in the radial part of the anchor lock (productive energy). The energy losses (non-productive energy) are used for the heating of the end part of the lock.

The purpose of the present work to determine the share of non-productive energy expenses for heating the rocks in the end part of anchor lock.

\section{Calculation method}

The indicator of energy efficiency of the new method of anchoring is the ratio of the thermal stream in the end part of the lock to the radial component of the thermal stream. The thermal stream in the end part and the cylindrical part (radial component) of the anchor lock can be determined using the following formulas:

$$
q_{1}=-\lambda \frac{\partial T}{\partial x} F_{1} \quad \text { and } \quad q_{2}=-\lambda \frac{\partial T}{\partial r} S_{1}
$$

Where: $q_{1}, q_{2}$ - thermal stream in the end part and the cylindrical part of the anchor lock, $\mathrm{J} / \mathrm{s} ; \lambda$ - thermal conductivity coefficient of the rocks, W/mK; $\mathrm{T}$ - temperature on the surface of the rocks, $\mathrm{K} ; F_{1}, S_{1}$ - area of the end part and the cylindrical part of anchor lock, $\mathrm{m} 2 ; \mathrm{x}, \mathrm{r}$ - coordinates, $\mathrm{m}$.

Correspondingly, the areas $F_{1}, S_{1}$ can be found from the following formulas:

$$
F_{1}=\pi \cdot d_{1}^{2} / 4 \quad \text { and } \quad S_{1}=\pi \cdot d_{1} \cdot h
$$

Where $\mathrm{d} 1$ - diameter of the tube, $\mathrm{m} ; \mathrm{h}$ - height of the anchor lock, $\mathrm{m}$. 
Introducing parameter $\beta$. This parameter characterizes the ratio of the thermal stream in the end part of the lock and in its cylindrical part. Plugging the parameter into formulas (1) and (2), the following expression is obtained:

$$
\beta=\frac{q_{1}}{q_{2}}=d_{1} / 4 h
$$

Areas $F_{1}$ and $S_{1}$ are variables changing up to values $F_{2}$ and $S_{2}$ respectively. $F_{2}$ and $S_{2}$ are the surface areas of the end part and the cylindrical part of the anchor lock after the teeth are opened. The anchor lock at the end of the process looks like a frustrum of a cone whose upper part is larger than the diameter of the tube. In this case, the radial thermal stream goes beyond the anchor lock and its linear calculation dimension will be equal to the slant heigh of the cone.

That is:

$$
F_{2}=\pi \cdot d_{2}^{2} / 4 \quad \text { and } \quad S_{2}=\pi\left(d_{1}+d_{2}\right) /(2 h \cdot \cos \alpha)
$$

The value of the parameter $\beta$ can be determined as the average value according to the formula:

$$
\beta=\left(F_{1}+F_{2}\right) /\left(S_{1}+S_{2}\right)
$$

Using the expressions (2) and (4) from (5), after several transformation, the following expression is obtained:

$$
\beta=0,5\left(1+n^{2}\right) /\left(2 j+(1+n) \sqrt{n^{2}+j^{2}}\right)
$$

Where $n=d_{2} / d_{1}$ and $j=h / d_{1}$.

\section{Analysis and discussion of results}

Consider the start of the rocks thawing process until the opening of the anchor lock teeth. In this case, the ratio of non-productive energy expenses (through the end part of the anchor) to productive energy expenses (which are used to thaw the rocks around the anchor teeth through the cylindrical part of the lock) is determined by the formula (3). On the figure 1 charts of dependence of the the parameter $\beta$ on the values $d_{1}$ and $h$ are presented.

As can be seen from the chart, the parameter $\beta$ has a maximum value from 0.09 to 0.22 at the lowest length of the anchor lock and a minimum value from 0.05 to 0.11 at the highest length of the anchor lock. The larger the diameter of the tube, the higher are the non-productive energy expenses. The longer is the anchor lock, the smaller is the share of the end part component of the heat exchange. This follows from a simple analysis of the formula (3). In this case we were interested not in the qualitative but in a quantitative component of the analysis of heat exchange process during the formation of the anchor lock. Analysis of the charts shows that in real conditions of the use of the new technology (a typical range of geometric parameters of anchors was used for the calculation) the changes of the determining parameter range from 0.05 to 0.22 . That is, even in the starting phase of the anchor lock formation there exists an area in which non-productive energy expenses (energy losses) exceed $10 \%$, this being the maximum permissible error in engineering calculations.

In the formation of the anchor lock we are interested only in the heat exchange process from the starting phase to the possible opening of the anchor teeth. Further heating of the rocks and the process of their freezing back is not relevant for the aims of this work. For this reason, the analysis of the variant calculations according to the formula (6) allows to 
answer the question how the non-productive energy expenses through the end part quantitatively impact the process of anchor lock formation from the starting phase till the opening of the anchor lock teeth as they are pushed into the thawing dispersed rocks. On figure 2 , the results of variant calculations according to the formula (6) are presented as a chart.

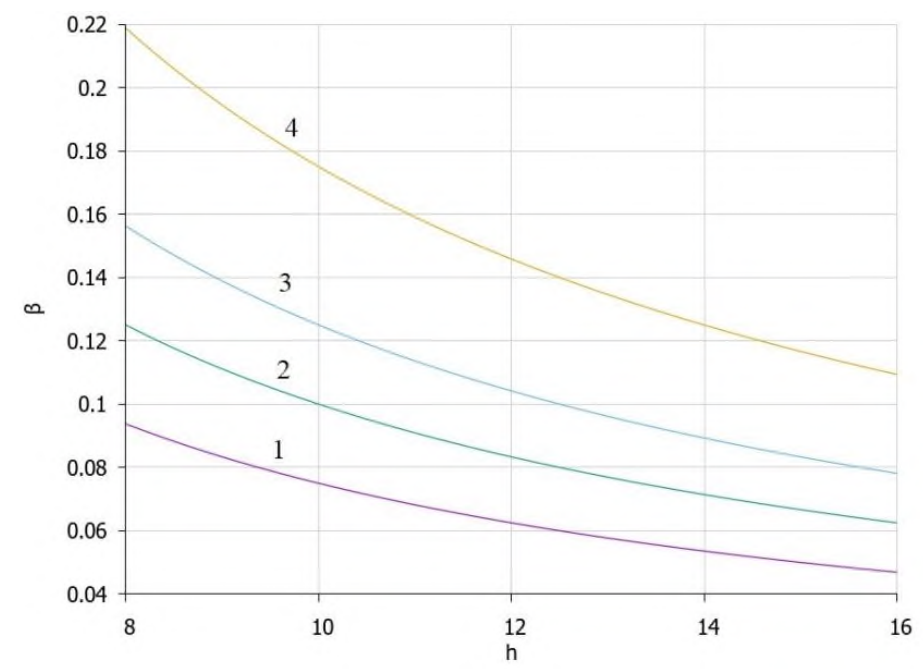

Fig. 1. Changes in the parameter $\beta$ depending on the length of the anchor lock part $\mathrm{h}(\mathrm{cm})$ with different diameters of the tube $d_{1}: 1-3 \mathrm{~cm} ; 2-4 \mathrm{~cm} ; 3-5 \mathrm{~cm} ; 4-7 \mathrm{~cm}$.

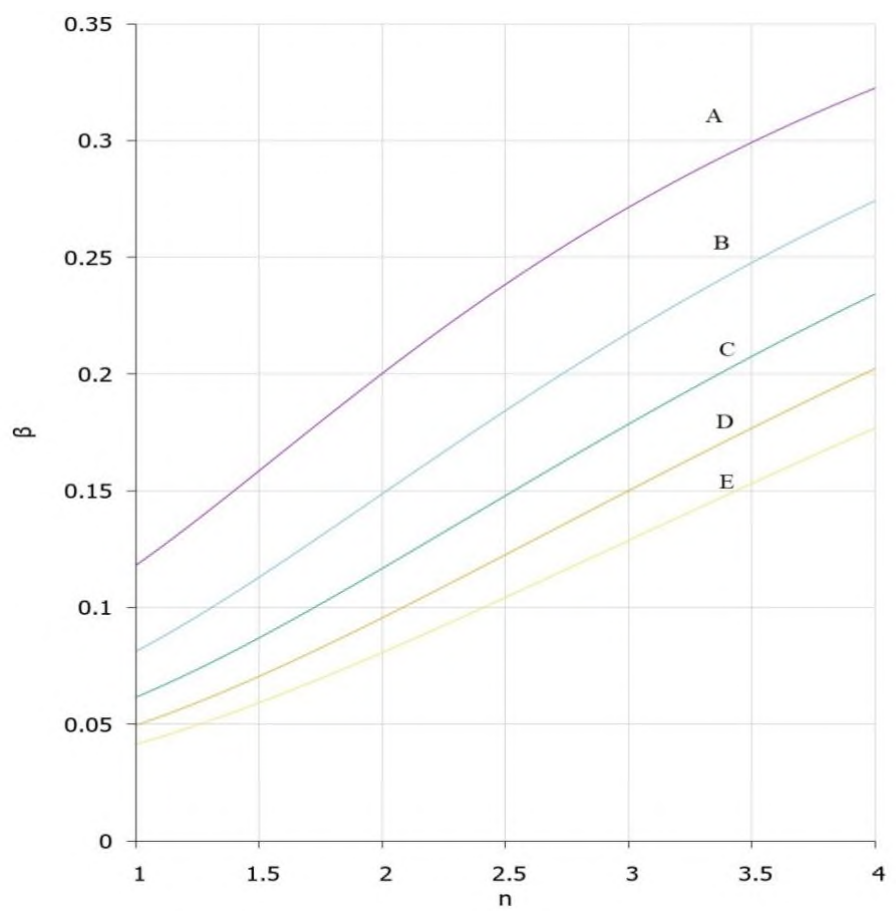

Fig. 2. Changes in the parameter $\beta$ depending on the extent of anchor lock teeth opening (parameter $n$ ) with different values of the ratio of the anchor lock length to the tube diameter (parameter $j$ ): $A-2$; $\mathrm{B}-3 ; \mathrm{C}-4 ; \mathrm{D}-5 ; \mathrm{E}-6$. 
As can be observed in the charts, the average non-productive energy expenses throughout the entire process of anchor lock formation can constitute up to $30 \%$ from the productive energy expenses for the anchor lock teeth opening. And the greater the extent of opening, the greater the non-productive energy expenses. It is necessary to note that the degree of the teeth opening determines the reliability of the anchor in real conditions. That is, if the non-productive energy expenses are decreased, the degree of the teeth opening will be greater and, correspondingly, the anchor fix of the mine workings will be more reliable. For this reason, an important direction of the future research into increasing the efficiency and expanding the area of application of the new anchoring method in the mine workings of the permafrost areas developed in dispersed rocks is to search for new technical and technological solutions to decrease the non-productive energy expenses in the end part of the anchor lock.

\section{Conclusion}

Simple mathematical dependencies to assess the share of thermal stream in the end part of the anchor lock (non-productive energy expenses) to the radial component (productive energy expenses) which determines the speed and efficiency of the new method of mine workings anchoring were obtained. It was shown that if the process of rocks thawing is only considered in the starting phase, the non-productive energy expenses can constitute, on average, no more than $10 \%$. If the process is considered including the opening of the anchor lock teeth to its final dimension, the non-productive energy expenses (energy losses) can be significantly higher - more than $30 \%$ and have significant impact on the effectiveness of the process of anchor lock formation and, as a consequence, on its future reliability. A further direction towards the improvement of the new method of anchoring of the mine workings in the permafrost areas and expanding its application area is the search for new technical and technological solutions to decrease the non-productive energy expenses during the formation of the anchor lock.

\section{References}

1. V.N. Skuba,Research on the stability of mine workings in permafrost conditions (Novosibirsk: Nauka, 1974)

2. V.A. Sherstov, Increasing the stability of mine workings in dispersed mine tunnels of the North (Novosibirsk: Nauka - Siberian Division, 1980)

3. G.P. Kuzmin, Underground structures in the permafrost areas (Novosibirsk: Nauka, 2002)

4. A.F. Galkin,Thermal regime of mine workings in the permafrost areas. Journal of the Mining Institute 219, 377-381 (2016) http://dx.doi.org/ 10.18454/pmi.2016.3.377

5. A.F. Galkin,Thermal conditions of the underground town collector tunnel, Metallurgical and Mining Industry, 70-73 (2015)

6. S.S. Vyalov,Reological foundations of the frozen soil mechanics (Moscow: VyschayaShkola, 1978)

7. N.A. Tsytovich, Frozen soil mechanics (Moscow: VyschayaShkola, 1973)

8. E.P. Shuscherina,Resistance of the frozen dispersed rocks to tearing in low temperatures (up to $-60^{\circ} \mathrm{C}$ ). Permafrost Research (1974) 
9. J. Teng, F. Shan, S. Zhang, D. Sheng,Numerical Modelling of Vapour-Ice Desublimation Process ICEG 2018, ESE, 560-568 (2019)nhttps://doi.org/10.1007/978981-13-2221-1_61

10. J. Teng, F. Shan, Z. He, S. Zhang, D. Sheng,Experimental study of ice accumulation in unsaturated clean sand, Géotechnique 69, 251-259 (2018) doi:10.1680/jgeot.17 https://doi.org/10.1680/jgeot.17.P.208

11. O. Andersland, B.Ladanyi, Frozen Ground Engineering. Wiley (2004)

12. D.M. Anderson, N.R. Morgenstern, Physics, chemistry, and mechanics of frozen ground: a review. In: North American Contribution Second International Conference on Permafrost (1973)

13. G. Xu, J. Qi, W. Wu, Temperature Effect on the Compressive Strength of Frozen Soils: A Review, Recent Advances in Geotechnical Research, Springer Series in Geomechanics and Geoengineering, 227-236 (2019) https://doi.org/10.1007/978-3319-89671-7_19

14. A.F. Galkin, V.V. Naumov, Efficiency of Using Lightweight Concrete in Mine Workings of the North, GeoConference on Science and Technologies in Geology. Exploration and Mining (14thSGEM),17-26, Albena, Bulgaria. Conference Proceedings.,Volume III, 199-203 (2014)

15. V.M. Vernigor, K.V. Morozov, V.N. Bobrovnikov, On the approach towards design of the thermal regime of the mine workins in the conditions of permafrost, Journal of the Mining Institute (205), 139-140 (2013)

16. E.T. Voronov, I.A. Bondar, Impact of the temperature factor on the safety and effectiveness of underground mining in permafrost areas, Bulletin of Chita State University 5(62), 85-93, (2010)

17. A.V. Dugartsyrenov, E.L. Belchenko, Parameters of thermal insulation in grounds freezing into the permitted depth,Mining information-analytical bulletin (technical journal) (5), 44-47 (2009)

18. A.F. Galkin, V.V. Eltsov, A.A. Marshalov, Anchor for mine workings fixing. Russian patent no. 2540708, (4) Bulletin (2015) [online, accessed 2021] https://www1.fips.ru/Archive/PAT/2015FULL/2015.02.10/DOC/RUNWC1/000/000/0 $\underline{\text { 02/540/708/DOCUMENT.PDF }}$ 